\title{
Superação da dormência em sementes de Plathymenia reticulata Benth.
}

\author{
Cássio do Prado BORGES ${ }^{1}$, Cheila Deisy FERREIRA², Daniela Pereira DIAS ${ }^{3 *}$ \\ ${ }^{1}$ Programa de Pós-graduação em Agronomia, Universidade Federal de Goiás - Regional Jataí, Jataí, GO, Brasil. \\ ${ }^{2}$ Programa de Pós-graduação em Ciências Florestais, Universidade de Brasília, Brasília, DF, Brasil. \\ ${ }^{3}$ Unidade Acadêmica Especial de Ciências Agrárias, Universidade Federal de Goiás - Regional Jataí, Jataí, GO, Brasil. \\ E-mail: danieladias@ufg.br
}

Recebido em maio/2018; Aceito em outubro/2018.

RESUMO: Este trabalho objetivou avaliar a germinação e vigor de sementes de Plathymenia reticulata Benth. submetidas a diferentes tratamentos para superação de dormência. Os tratamentos testados foram: controle sementes intactas (T0), escarificação mecânica com lixa d'água $\mathrm{n}^{\circ} 60$ (T1), desponte na região lateral do tegumento (T2), imersão em água fervente por $10 \mathrm{~min}$ (T3), em hipoclorito de sódio por 15 min (T4) e em solução com detergente por 15 min (T5). Foram determinados: peso de mil sementes, grau de umidade, porcentagem de germinação, índice de velocidade de germinação (IVG), tempo médio de germinação (TMG), curva de embebição, teste da condutividade elétrica e comprimento da radícula. A porcentagem de germinação das sementes submetidas ao T1 e T2 foi estatisticamente igual (respectivamente, 90 e 88\%) e superiores aos outros tratamentos testados (12\%). As sementes expostas aos T1 e T2 apesentaram porcentagem de absorção de água superiores e em menor tempo, assim como maiores IVG e menores TMG, comparadas aos demais tratamentos. O comprimento das radículas não variou entre os tratamentos testados. A condutividade elétrica da solução com as sementes do T0 foi superior aos outros tratamentos testados. Sementes de P. reticulata expostas ao T1 e T2 apresentam maior germinação e vigor.

Palavras-chave: germinação, índice de velocidade de germinação, teste de condutividade elétrica, vigor, vinhático.

\section{Dormancy breaking of Plathymenia reticulata Benth. seeds}

\begin{abstract}
This study aimed to evaluate the germination and vigor of Plathymenia reticulata Benth. seeds submitted to different dormancy breaking treatments. Testing treatments were: control - intact seeds (T0); mechanical scarification with sandpaper n. 60 (T1), coating cutting in the lateral side of tegument (T2), immersion in boiling water during $10 \mathrm{~min}$ (T3), in sodium hypochlorite solution during $15 \mathrm{~min}$ (T4), and in detergent solution during $15 \mathrm{~min}$ (T5). Moisture content, 1000-seed weight, germination percentage, germination speed index (GSI), mean germination time (MGT), imbibition curve, electrical conductivity test, and radicle length were determined. Germination percentage to T1 and T2 were statistically equal (90 and $88 \%$, respectively) and higher than others treatments tested (12\%). Seeds exposed to T1 and T2 also presented higher and faster water absorption percentage, when compared to the others treatments, as well as higher GSI, and lower MGT. The rootlets length did not vary among treatments tested. Electrical conductivity of intact seeds was higher than others treatments. $P$. reticulata seeds expose to T1 e T2 had highest germination percentage and vigor.

Keywords: germination, germination speed index, electrical conductivity test, vigor, vinhático.
\end{abstract}

\section{INTRODUÇÃO}

O vinhático (Plathymenia reticulata Benth.) é uma espécie arbórea nativa dos biomas Amazônia, Caatinga, Cerrado e Mata Atlântica, com ampla distribuição geográfica (FREIRE et al., 2017). Possui crescimento rápido, atinge altura total entre 20 a 30 metros e diâmetro a altura do peito de 30 a 150 $\mathrm{cm}$, variando em função do bioma em que se encontra (CARVALHO, 2009).

Entre outras possibilidades, esta espécie pode ser utilizada para fins madeireiros devido à boa qualidade da sua madeira $\mathrm{e}$ resistência natural a organismos xilófagos (BOUCHARDET et al., 2015) e apresenta potencial para ser utilizada na recuperação de áreas degradadas (BRAGA et al., 2007). Devido à sua capacidade de habitar diferentes ambientes e possibilidades de usos, estudos com sementes de vinhático se tornam necessários, sobretudo visando a produção de mudas.
As sementes são o principal meio de propagação de espécies florestais, porém algumas possuem dormência, característica indesejável para produção de mudas, por promover menor uniformidade, maior tempo de exposição à condições adversas e maior risco de perda de sementes por deterioração (AZEREDO et al., 2010). Em sementes de espécies da família Fabaceae é comum a ocorrência de dormência física, causada pela impermeabilidade do tegumento, como verificado para o vinhático (FREIRE et al., 2017).

Várias técnicas tem sido utilizadas para superação da dormência em sementes de vinhático, sendo a escarificação mecânica (com uso de lixa) das sementes a técnica mais indicada, onde ocorre maior porcentagem de germinação (FONSECA et al., 2013; LOPES et al., 2010; BOUCHARDET et al., 2015). Entretanto, a superação da dormência por meio 
de outros métodos tem sido experimentada em outras espécies, como o desponte e o uso de hipoclorito de sódio e detergente (AMÉRICO et al., 2011, BENEDITO et al. 2009, OLIVEIRA et al., 2012, SMIDERLE; SCHWENGBER, 2011). Considerando que a escarificação das sementes com lixa pode ser uma atividade trabalhosa e irregular, testar outras metodologias para superação de dormência tegumentar das sementes de vinhático pode simplificar a produção de mudas da espécie e possibilitar uma germinabilidade igual ou superior.

Apesar do teste de germinação ser o mais utilizado para avaliar a qualidade fisiológica das sementes, não é capaz de identificar diferença entre lotes de sementes quanto a eficiência das sementes no campo, principalmente entre aqueles com padrão de germinação alto e similar (BARBOSA et al., 2012). Desta forma, é importante avaliar o vigor das sementes como complemento ao teste de germinação. Vários testes podem ser utilizados para avaliação do vigor das sementes. Entre eles, são citados os testes de envelhecimento acelerado, condutividade elétrica, frio, lixiviação de potássio e pH de exsudato, bem como o comprimento das plântulas. O teste de condutividade elétrica destaca-se, devido a sua maior rapidez, facilidade de execução, alta reprodutibilidade e eficácia na separação de lotes de sementes quanto ao seu vigor (DELAZERI et al., 2016). Adicionalmente, por meio do crescimento de plântulas, é possível avaliar a qualidade das sementes rapidamente, sem a necessidade de equipamentos especiais ou treinamento especializado e com baixo investimento (VANZOLINI et al., 2007).

Assim, o objetivo deste trabalho foi avaliar a germinação e vigor de sementes de Plathymenia reticulata Benth. submetidas a diferentes tratamentos para superação de dormência.

\section{MATERIAL E MÉTODOS}

Os frutos de vinhático foram coletados no Parque Estadual

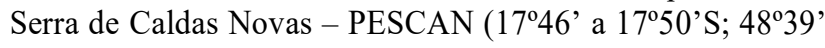
a 48 $44^{\prime}$ 'O), região sudeste de Goiás, em agosto de 2015. A coleta dos frutos, maduros e de coloração amarronzada, foi realizada em sete árvores matrizes. Após a coleta, os frutos foram transportados para o Laboratório de Sementes Florestais da Universidade Federal de Goiás - Regional Jataí, e as sementes extraídas manualmente, sendo excluídas as malformadas e danificadas.

Foi determinado o peso de mil sementes a partir da contagem de oito subamostras de 100 sementes (BRASIL, 2009). Realizou-se, também, a determinação do grau de umidade pelo método da estufa a $105 \pm 3^{\circ} \mathrm{C}$ durante 24 horas (BRASIL, 2009).

Para a avaliação da germinação, além do tratamento controle (sementes intactas - tratamento 0), as sementes foram submetidas a tratamentos para a superação de dormência: escarificação com lixa $n^{0} 60$ na região lateral do tegumento (tratamento 1), desponte na região lateral do tegumento com auxílio de uma tesoura (tratamento 2), imersão em água fervente por $10 \mathrm{~min}$ (tratamento 3), em solução com hipoclorito de sódio $(20 \mathrm{ml}$ de hipoclorito e 80 de água destilada) por 15 min (tratamento 4) e em solução com detergente ( 5 gotas de detergente em $100 \mathrm{ml}$ de água destilada) por 15 min (tratamento 5). As sementes imersas em solução com detergente e hipoclorito de sódio foram lavadas em água corrente e secas em papel toalha após exposição ao tratamento.
Foram utilizadas quatro repetições de 25 sementes em cada tratamento.

O teste de germinação, conduzido em germinador do tipo $\mathrm{BOD}$, foi realizado em temperatura constante $\left(25{ }^{\circ} \mathrm{C}\right)$ e fotoperíodo de 12 horas, conforme Lopes et al. (2010). Discos de papel filtro (três camadas) foram umedecidos com água destilada ao equivalente a 2,5 vezes o peso dos discos secos, em placas de Petri esterilizadas. Quando necessário, os discos de papel com as sementes foram reumedecidas.

O teste de germinação durou 14 dias e as contagens do número de sementes germinadas foram realizadas diariamente. Foram consideradas germinadas as sementes que apresentaram protrusão de radícula ( $\geq 2 \mathrm{~mm}$ ), sendo os resultados expressos em porcentagem. Juntamente com o teste de geminação, foram calculados o índice de velocidade de germinação (IVG) e o tempo médio de germinação (TMG), determinados de acordo com Maguire (1962) e Labouriau (1983), respectivamente.

As plântulas foram analisadas, quanto ao comprimento da radícula, 14 dias após o início do experimento, com auxílio de um paquímetro digital, sendo os dados expressos em $\mathrm{mm}$.

Paralelamente, as curvas de embebição das sementes foram determinadas para as condições testadas (tratamentos para superação de dormência). Foram utilizadas quatro repetições de dez sementes para cada tratamento estudado. As sementes foram pesadas em balança analítica de precisão $(0,0001 \mathrm{~g})$ e imersas em $50 \mathrm{ml}$ de água destilada $\left(25^{\circ} \mathrm{C}\right)$. A porcentagem de absorção de água (curva de embebição) das sementes foi avaliada nos seguintes intervalos: $0,2,4,8,10$, $12,24,48,72,96,120 \mathrm{~h}$, considerando o peso inicial das sementes.

Para avaliar a viabilidade das sementes pelo teste de condutividade elétrica, as sementes foram pesadas e imersas em $50 \mathrm{~mL}$ de água destilada mantidas em temperatura de $25^{\circ} \mathrm{C}$ (VIDIGAL et al., 2008). A leitura da condutividade foi realizada em 0, 24, 48, 72 e 96 horas após o início da embebição. Foi utilizado um condutivímetro de bancada (SPIN-C3010) e os resultados de cada leitura foram divididos pelo peso de cada subamostra, sendo expressos em $\mu \mathrm{S} \mathrm{cm}^{-1} \mathrm{~g}$

Como os dados não atenderam aos pressupostos de normalidade e homocedasticidade, nem mesmo com a transformação dos mesmos, foi utilizada a análise não paramétrica. Os dados foram submetidos ao teste de KruskalWallis e, posteriormente, a comparação das médias foi realizada pelo método de Dunn ao nível de 5\% de significância. As análises estatísticas foram realizadas utilizando-se o software Bioestat 5.0.

\section{RESULTADOS}

$\mathrm{O}$ peso de mil sementes, o número de sementes por $\mathrm{kg}$ e o grau de umidade determinados para sementes de vinhático foram de, respectivamente, $42,45 \mathrm{~g} \pm 0,32,23557$ sementes $\mathrm{kg}^{-}$ ${ }^{1}$ e $8,42 \%$. A porcentagem de germinação das sementes de vinhático variou de 12 a $90 \%$, de acordo com o tratamento de superação da dormência (Figura 1A).

Para as sementes intactas e as que passaram pela imersão em água quente, hipoclorito e detergente (T0, T3, T4 e T5), a porcentagem de germinação não apresentou diferença significativa. Por outro lado, estes tratamentos foram estatisticamente diferentes daqueles em que as sementes foram escarificadas com lixa e com desponte (T1 e T2).

O início da germinação das sementes ocorreu no quarto dia após o início do teste de germinação de todos os tratamentos 
para superação de dormência, exceto para T0 (iniciou no quinto dia). A germinação das sementes ocorreu entre o quarto e o $14^{\circ}$ dia após o início do teste e as sementes submetidas ao T1 e T2 apresentaram maior número de sementes germinadas entre o quinto e sexto dia após o início do experimento $(77,27$ e $95,56 \%$, respectivamente).

Assim como ocorreu para a porcentagem de germinação, as sementes submetidas ao T1 e T2 também apresentaram valores do índice de velocidade de germinação estatisticamente similares e superiores aos demais tratamentos (Figura 1B). O tempo médio de germinação foi menor em T1 e T2, quando comparado aos outros tratamentos (Figura 1C).
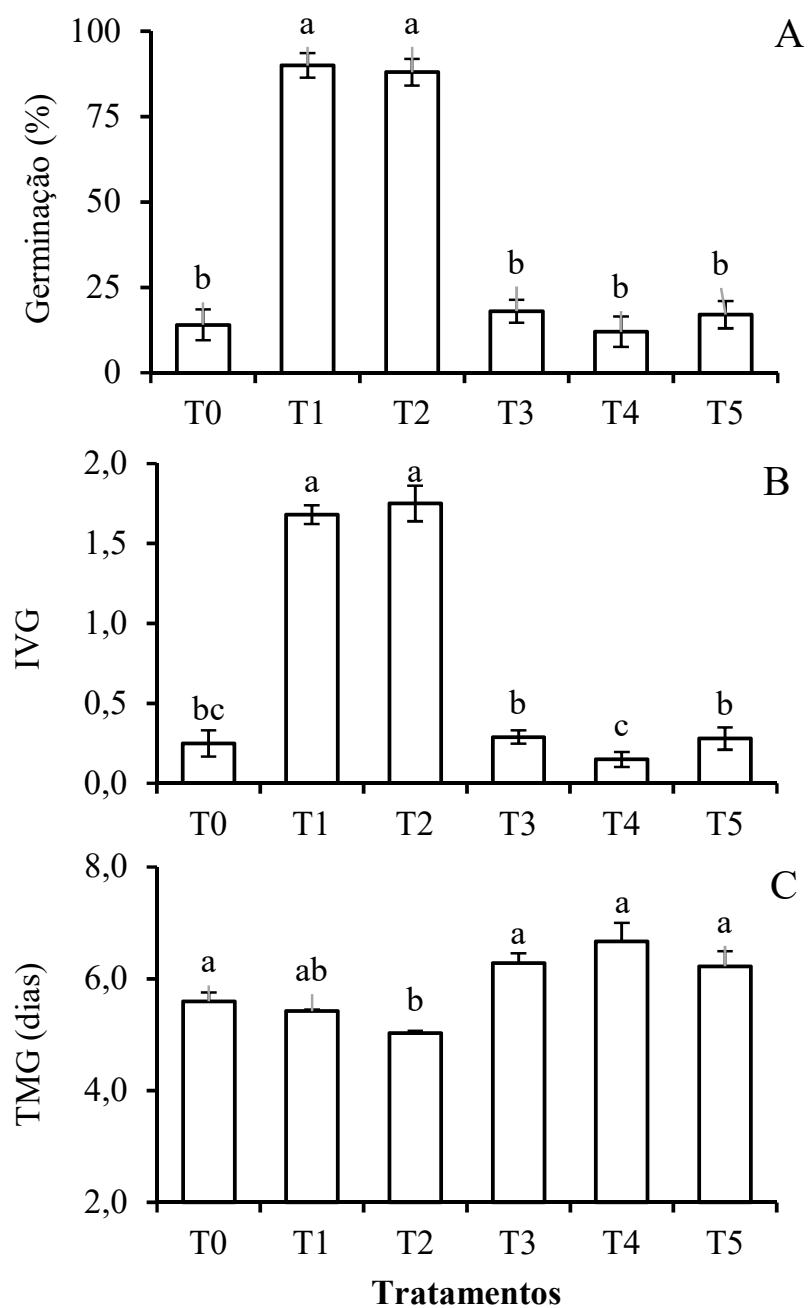

Figura 1. Germinação (\%), índice de velocidade de germinação (IVG) e tempo médio de germinação (TMG, em dias) de sementes intactas (T0) de Plathymenia reticulata e submetidas a tratamentos para a superação de dormência: escarificação com lixa ${ }^{\circ} 60$ na região lateral do tegumento (T1), desponte na região lateral do tegumento com auxílio de uma tesoura (T2), imersão em água fervente por $10 \mathrm{~min}$ (T3), em solução com hipoclorito de sódio (20 $\mathrm{ml}$ de hipoclorito e 80 de água destilada) por 15 min (T4) e em solução com detergente (5 gotas de detergente em $100 \mathrm{ml}$ de água destilada) por $15 \mathrm{~min}$ (T5). Figure 1. Germination (\%), germination speed index (IVG), mean germination time of intact seeds of Plathymenia reticulata (T0) and submitted to dormancy breaking treatments: scarification with sandpaper number 60 on one side of the seed (T1), coating cutting on one side of the seed (T2), boiling water immersion for $10 \mathrm{~min}$ (T3), immersion in detergent solution $(20 \mathrm{~mL}$ of sodium hypochlorite in $80 \mathrm{~mL}$ of distilled water) for $15 \mathrm{~min}$ (T4) and in sodium hypochlorite solution (5-drop of sodium hypochlorite in $100 \mathrm{~mL}$ of distilled water) for $15 \min (\mathrm{T} 5)$.
A absorção de água (embebição) pelas sementes de vinhático variou em função do tempo e dos diferentes tratamentos para superação de dormência (Figura 2).

As sementes de vinhático submetidas aos T1 e T2 apresentaram incrementos rápidos na absorção de água nas primeiras 24 horas, com estabilização após 48 horas (Figura 2). Neste período as sementes expostas aos tratamentos citados absorveram um volume de água superior a $150 \%$ do seu peso inicial. Por outro lado, as sementes expostas ao T3, após 120 horas, absorveram $100 \%$ de água em relação ao seu peso inicial (Figura 2). Os tratamentos T0, T4 e T5, após o período de 24 horas, apresentaram absorções praticamente constantes e menores que os demais tratamentos (Figura 2). T0, T4 e T5 foram os tratamentos em que as sementes absorveram menores quantidades de água ao longo do período analisado, atingindo, após $120 \mathrm{~h}$, aproximadamente $50 \%$ em relação a sua massa inicial.

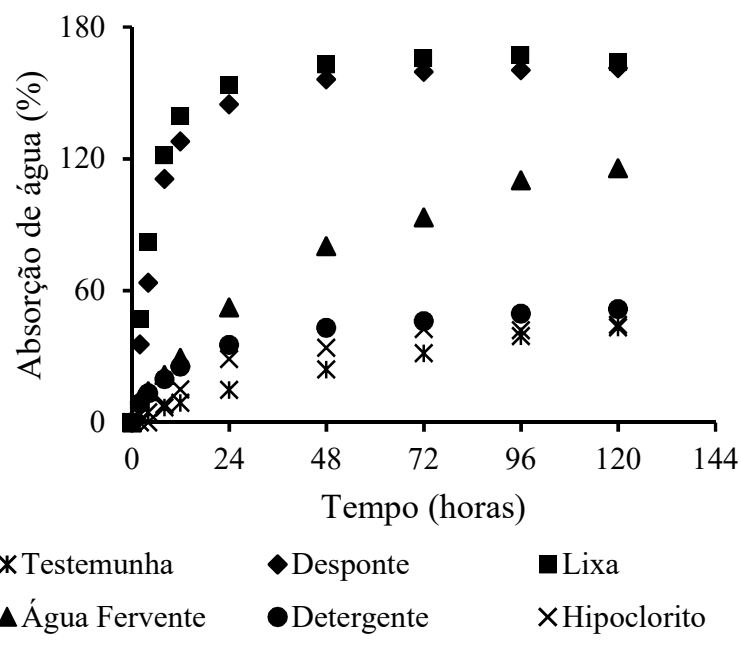

Figura 2. Absorção de água (embebição) sementes intactas (T0) de Plathymenia reticulata e submetidas a tratamentos para a superação de dormência: escarificação com lixa $n^{\circ} 60$ na região lateral do tegumento (T1), desponte na região lateral do tegumento com auxílio de uma tesoura (T2), imersão em água fervente por $10 \mathrm{~min}$ (T3), em solução com hipoclorito de sódio $(20 \mathrm{ml}$ de hipoclorito e 80 de água destilada) por $15 \mathrm{~min}$ (T4) e em solução com detergente (5 gotas de detergente em $100 \mathrm{ml}$ de água destilada) por $15 \mathrm{~min}$ (T5).

Figure 2. Imbibition curve of intact seeds of Plathymenia reticulata (T0) and submitted to dormancy breaking treatments: scarification with sandpaper number 60 on one side of the seed (T1), coating cutting on one side of the seed (T2), boiling water immersion for 10 min (T3), immersion in detergent solution $(20 \mathrm{~mL}$ of sodium hypochlorite in $80 \mathrm{~mL}$ of distilled water) for $15 \mathrm{~min}$ (T4) and in sodium hypochlorite solution (5-drop of sodium hypochlorite in $100 \mathrm{~mL}$ of distilled water) for $15 \mathrm{~min}(\mathrm{~T} 5)$.

A solução com sementes expostas ao T0 e T2 apresentaram os maiores valores de condutividade elétrica (CE) em todos os períodos analisados (Figura 3A), atingindo valores máximos após 24 e $48 \mathrm{~h}$ do início do teste, respectivamente, mantendose constantes até $96 \mathrm{~h}$. A CE da solução das sementes submetidas aos outros tratamentos aumentou em função do tempo (Figura 3B). Após 96 h, a CE da solução das sementes submetidas ao $\mathrm{T} 0$ apresentou os maiores valores, seguido de T2, T5, T4, T1 e T3.

Em relação ao comprimento da radícula, não houve diferença entre os tratamentos ( $p=0,054$; Figura 4). O 
comprimento médio da radícula de vinhático, após 10 dias do início da germinação, foi de $17,0 \mathrm{~mm}$.
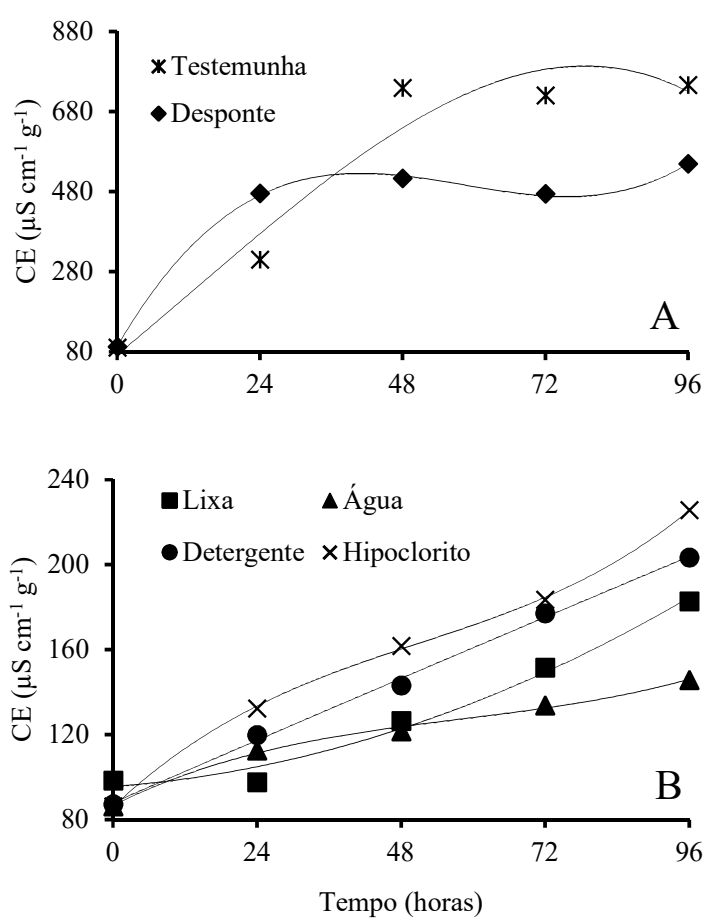

Figura 3. Condutividade elétrica em sementes de Plathymenia reticulata imersas em solução $\left(\mu \mathrm{S} \mathrm{cm}^{-1} \mathrm{~g}^{-1}\right)$ submetidas a tratamentos para superação de dormência.

Figure 3. Electrical conductivity of Plathymenia reticulata seeds soaking solution $\left(\mu \mathrm{S} \mathrm{cm}^{-1} \mathrm{~g}^{-1}\right)$ submitted to dormancy breaking treatments.

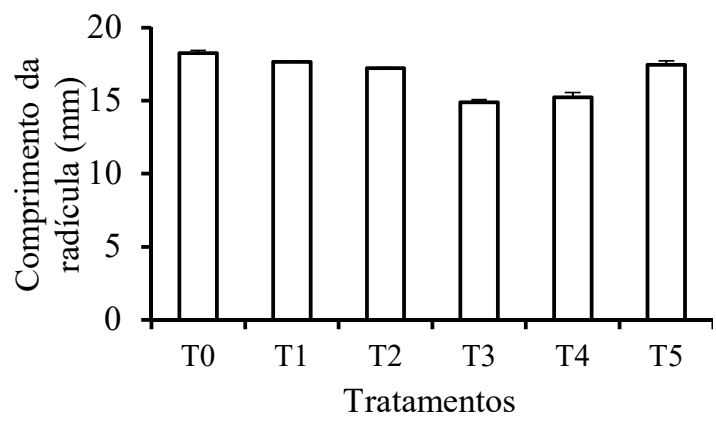

Figura 4. Comprimento da radícula $(\mathrm{mm})$ de Plathymenia reticulata após 14 dias do início da germinação das sementes submetidas a tratamentos para superação de dormência $(\mathrm{T} 0=$ sementes intactas; $\mathrm{T} 1$ = escarificação com lixa; T2 = desponte; $\mathrm{T} 3$ = imersão em água fervente; T4 = imersão em solução de hipoclorito de sódio, T5 = imersão em água com detergente).

Figure 4. Root length of Plathymenia reticulata assessed 14-days after germination start of seeds submitted to dormancy breaking treatments $(\mathrm{T} 0=$ intact seeds; $\mathrm{T} 1=$ scarification with sandpaper; $\mathrm{T} 2$ = coating cutting; $\mathrm{T} 3$ = boiling water immersion; $\mathrm{T} 4=$ immersion in sodium hypochlorite solution; T5 = immersion in detergent solution).

\section{DISCUSSÃO}

$\mathrm{O}$ peso de mil sementes pode ser relacionado com o tamanho das sementes, seu estado de maturidade e de sanidade (BRASIL, 2009). Além disso, o cálculo do número de sementes por embalagem e as análises de pureza são realizados a partir da determinação do peso de mil sementes (BRASIL, 2009). O peso de mil sementes de vinhático, obtida neste estudo, foi 15,2\% superior ao encontrado por Fonseca et al.
(2013). Isto pode ocorrer devido à maior quantidade de água encontrada no interior das sementes, o que as torna mais densas e pesadas ou ainda, devido à variação das dimensões das sementes, de acordo com o local onde foi coletada, ou ao seu grau de maturidade. $\mathrm{O}$ número de sementes. $\mathrm{kg}^{-1}$ encontrado neste estudo está de acordo com o esperado, variando de 15000 a 33200 sementes. kg $^{-1}$ (CARVALHO, 2009).

O grau de umidade de sementes de vinhático apresentado por Lopes et al. (2010), considerando as espécies Plathymenia reticulada e Plathymenia foliolosa Benth. como diferentes ecótipos de Cerrado e Mata Atlântica, foram de, respectivamente, $11,4 \% \pm 0,3$ e $10,1 \% \pm 0,8$, ambos valores superiores aos encontrados neste estudo. Vários fatores podem influenciar os diferentes graus de umidade de sementes de uma mesma espécie, inclusive a adoção de diferentes métodos de determinação do grau de umidade, como os adotados neste estudo e os realizados por Lopes et al. (2010).

Houve ampla variação da porcentagem de germinação entre os tratamentos (12 a 98\%), superior ao observado por Fonseca et al. (2013), onde o coeficiente de variação da porcentagem de germinação de vinhático foi de $23,5 \%$. Estes autores encontraram germinação variando entre 0 e 14\% nos diferentes tratamentos pré-germinativos utilizados para superação de dormência. Lopes et al. (2010) mostraram que as porcentagens de germinação das sementes intactas aumentaram com a temperatura. Por exemplo, 93\% das sementes intactas de vinhático germinaram a $30^{\circ} \mathrm{C}$ e $55 \%$ a $25^{\circ} \mathrm{C}$, em ambos os casos sob fotoperíodo de $12 \mathrm{~h}$. Além disso, as sementes não escarificadas apresentaram maior germinabilidade a partir de $30^{\circ} \mathrm{C}(12 / 12 \mathrm{~h})$, com valores superiores a $62 \%$ de germinação.

$O$ início da germinação de vinhático verificada neste estudo corrobora com os resultados apresentados por Fonseca et al. (2013), onde no quarto dia após a semeadura foi observada a emergência de $P$. foliolosa. As sementes que apresentam tempo de germinação mais delongados tem sido compreendidas como indicativo de adaptação a ambientes menos favoráveis.

Estudando a interação entre três métodos de superação de dormência (testemunha, lixa e ácido sulfúrico) e diferentes termoperíodos, Lopes et al. (2010) observaram diferença significativa entre os métodos somente na temperatura de $25^{\circ} \mathrm{C}$, com maior porcentagem de germinação para sementes escarificadas com lixa d'água. Braga et al. (2007) estudaram a influência do tempo de armazenamento na germinação, e também relataram uma maior porcentagem de sementes germinadas quando estas foram escarificadas com lixa. $\mathrm{O}$ uso da lixa para superação da dormência de vinhático tem se mostrado muito eficiente, o que, neste estudo, se equipara a outro método, aquele onde foi realizado um desponte lateral das sementes. Outras espécies da sub-família Mimosoidae e Caesalpinioideae também apresentaram resultados com o uso de lixa e desponte de sementes, tais como Senna corymbosa Lam. (SANTOS et al., 2008), Dimorphandra mollis Benth. (OLIVEIRA et al., 2008), Parkia platycephala Benth. (NASCIMENTO et al., 2009), Samanea tubulosa Benth. (GIACHINI et al., 2010) e Adenanthera pavonina L. (MANTOAN et al., 2012).

A baixa porcentagem de germinação das sementes expostas aos tratamentos T0, T3, T4 e T5 nos permite inferir que estes não foram suficientes para promover a superação de dormência das sementes da espécie estudada. Ou ainda, que, 
no caso das sementes submetidas à água fervente, esta pode ter gerado danos nas sementes que impediram sua germinação, apesar disso não ser esperado neste estudo. Dessa forma, o efeito da água fervente na superação de dormência de $P$. reticulata deve ser especificamente investigado, sobretudo em relação ao tempo de exposição das sementes à água fervente e qual a temperatura ideal da água.

O tempo de imersão das sementes, a elevada temperatura utilizada (imersão em água fervente), ou a concentração da solução com detergente e hipoclorito de sódio, podem explicar a baixa porcentagem de germinação. A redução na porcentagem de germinação em função de altas temperaturas da água foi verificada em outras espécies da sub-família Mimosoidae e Caesalpinioideae, tais como: Senna corymbosa Lam. (SANTOS et al., 2008), Senna multijuga (Rich.) Irwin et Barn (PIVETA et al., 2010), Parkia gigantocarpa Ducke. (OLIVEIRA et al., 2012) e Plathymenia foliosa Benth. (FONSECA et al., 2013).

De acordo com Piveta et al. (2010) o uso de água quente na superação de dormência e seu efeito sobre as sementes ainda não é bem conhecido, sendo que lotes de sementes de uma mesma espécie podem apresentar respostas diferentes quando submetidas a este tipo de tratamento. Assim como neste estudo, Benedito et al. (2009) encontraram baixa porcentagem e velocidade de germinação quando as sementes de Albizia lebbeck (L.) Benth. foram imersas em solução com hipoclorito de sódio, mesmo por diferentes períodos de tempo. Por outro lado, a imersão das sementes de paricana (Bowdichia virgilioides Kunth.) em hipoclorito de sódio por 1 minuto, após a imersão das sementes em água, facilitou a embebição e reduziu a deterioração das sementes (SMIDERLE; SCHWENGBER, 2011).

Outros estudos devem ser realizados visando associar o uso de hipoclorito de sódio com outra técnica de superação de dormência ou até mesmo testar maior concentração ou maior tempo de imersão das sementes. Da mesma maneira, o uso detergente deve ser melhor investigado. Sementes de Piper hispidinervum C.DC. expostas a diferentes temperaturas e lavadas com detergente tiveram maior germinação e maior índice de velocidade de germinação em temperaturas igual ou superior a $25^{\circ} \mathrm{C}$, porém sem efeito da lavagem das sementes com detergente (AMÉRICO et al., 2011).

Pereira; Ferreira (2010) relataram que tratamentos com escarificação mecânica e desponte em sementes de Parkia discolor Benth. apresentaram maior índice de velocidade de germinação em relação aos outros métodos analisados. Alves et al. (2008) também obtiveram maior índice de velocidade de germinação quando submeteram as sementes de Schinopsis brasiliense Engl. à escarificação mecânica. Por outro lado, em Plathymenia foliosa Benth., Fonseca et al. (2013) observaram que não houve diferença entre a porcentagem de germinação e índice de velocidade de germinação em sementes escarificadas e não escarificadas. Alguns métodos testados neste estudo também não diferiram do comportamento das sementes intactas, mesmo passando por tratamento pré-germinativo de superação de dormência (água quente, hipoclorito e detergente), provavelmente devido à incapacidade destes métodos em realmente vencerem a impermeabilidade do tegumento, causa da dormência das sementes de vinhático. A rápida e maior absorção de água pelas sementes levam à maior eficiência do processo germinativo, como esperado, fato que ocorreu com as sementes que passaram pelos T1 e T2.
Vários são os fatores que podem afetar os resultados do teste de condutividade elétrica (CE), entre eles: qualidade da água, temperatura e duração do período de embebição, grau de umidade da semente, número de sementes testadas e genótipo (VIDIGAL et al., 2008). Além disso, podemos acrescentar que as técnicas utilizadas para a superação de dormência de vinhático influenciaram nos valores do teste. Quanto maior o valor de $\mathrm{CE}$, os tegumentos liberaram maiores quantidades de lixiviados, o que ocorre devido à desestabilidade da membrana, aumentando sua permeabilidade (DALANHOL et al., 2014). As sementes intactas apresentaram os maiores valores no teste de CE, em comparação aos outros tratamentos, supostamente por terem sido menos manipuladas (lavadas).

$\mathrm{O}$ comprimento de plântulas ou de suas partes (aérea e radicular) tem sido empregado como método de avaliação de vigor de sementes, de acordo com sua qualidade fisiológica (VANZOLINI et al. 2007). Como não houve diferença estatística entre o comprimento das radículas após a germinação das sementes submetidas aos diferentes tratamentos para superação da dormência de vinhático, podemos sugerir que as sementes utilizadas que germinaram tinham boa qualidade fisiológica. Este resultado foi corroborado por Fonseca et al. (2013), que observaram que o comprimento da radícula emitidas de sementes de Plathymenia foliolosa Benth. não apresentou diferença significativa entre os métodos de superação de dormência utilizados, com o comprimento da radícula variando entre 1,86 e $3,25 \mathrm{~cm}$.

A superação da dormência em sementes de $P$. reticulata com o uso de lixa e o desponte promoveu maior porcentagem e velocidade de germinação, também associada com embebição, em menor tempo. A associação destas variáveis indica que estes tratamentos podem contribuir com a produção de mudas em condição de viveiro de forma mais homogênea e rápida.

\section{CONCLUSÕES}

A superação da dormência por meio da escarificação mecânica com lixa d'água $n^{\circ} 60$ (T1) e do desponte na região lateral do tegumento (T2) das sementes de $P$. reticulata promovem maior germinação e vigor.

\section{AGRADECIMENTOS}

À Fundação de Amparo à Pesquisa do Estado de Goiás (FAPEG).

\section{REFERÊNCIAS}

ALVES, A. F.; ALVES, A. F.; GUERRA, M. E. C.; FILHO, S. M. Superação de dormência de sementes de braúna (Schinopsis brasiliense Engl.). Revista Ciência Agronômica, Fortaleza, v. 38, n. 1, p. 74-77, 2008.

AMÉRICO, F. K. A.; BARBOSA, J. C. R. C. M.; CURI, C. C. S; NEGREIROS, J. R. S.; CARREGARO, J. B.; ROVERIJOSÉ, S. C. B. Estudo de parâmetros para realização de teste de germinação de sementes em duas espécies do gênero piper: Piper hispidinervum C.DC. e Piper aduncum. Ensaios e Ciência: Ciências Biológicas, Agrárias e da Saúde, v. 15, n. 2, p. 33-45, 2011.

AZEREDO, G. A.; PAULA, R. C.; VALERI, S. V.; MORO, F. V. Superação de dormência de sementes de Piptadenia moniliformis Benth. Revista Brasileira de Sementes, Brasília, v. 32, n. 2, p. 49-58, 2010. 
BARBOSA, R. M.; SILVA, C. B.; MEDEIROS, M. A. P. C.; VIEIRA, R. B. Condutividade elétrica em função do teor de água inicial de sementes de amendoim. Ciência Rural, Santa Maria, v. 42, n. 1, p. 45-51, 2012. DOI: http://dx.doi.org/10.1590/S0103-84782012000100008

BENEDITO, C. P.; RIBEIRO, M. C. C.; DE OLIVEIRA, M. K. T.; GUIMARÃES, I. P.; RODRIGUES, G. S. O. Influência da cor e métodos de superação de dormência em sementes de albizia. Revista Caatinga, Mossoró, v. 22, n. 2, p. 119-122, 2009.

BOUCHARDET, D.A.; RIBEIRO, I. M.; SOUSA, N. A.; AIRES, S. S.; MIRANDA, H. S. Efeito de altas temperaturas na germinação de sementes de Plathymenia reticulata Benth. e Dalbergia miscolobium Benth. Revista Árvore, Viçosa, v. 39, n. 4, p. 697-705, 2015. DOI: http://dx.doi.org/10.1590/0100-67622015000400012

BRAGA, L. L.; TOLENTINO, G. S., SANTOS, M. R. VELOSO, M. D. M.; NUNES, Y. R. F. Germinação de Sementes de Plathymenia reticulata Benth. (FabaceaeMimosoideae) sob Influência do Tempo de Armazenamento. Revista Brasileira de Biociências, Londrina, v. 5, n. 2, p. 258-260, 2007.

BRASIL Ministério da Agricultura, Pecuária e Abastecimento. Regras para análise de sementes. Brasília: MAPA/ACS, 2009. 399p.

CARVALHO, P. E. R. Vinhático - Plathymenia reticulata. Colombo: Embrapa Florestas, 2009. 11 p. (Comunicado Técnico, 231).

DALANHOL, S. J.; REZENDE, E. H.; ABREU, D. C. A.; NOGUEIRA, A. C. Teste de condutividade elétrica em sementes de Bowdichia virgilioides Kunth. Floresta e Ambiente, Seropédica, v. 21, n. 1, p. 69-77, 2014. DOI: http://dx.doi.org/10.4322/floram.2014.013

DELAZERI, P.; GARLET, J.; SOUZA, G. F. Teste de condutividade elétrica em lotes de sementes de Schinus molle L. Floresta e Ambiente, v. 23, n .3, p. 413-417, 2016. DOI: http://dx.doi.org/10.1590/2179-8087.142615

FONSECA, M. D. S.; DE FREITAS, T. A. S.; MENDONÇA, A. V. R.; SOUZA, L. S.; ABDALLA, S. D. Morfometria de sementes e plântulas e verificação da dormência da espécie Plathymenia foliolosa Benth. Comunicata Scientiae, v. 4, n. 4, p. 368-376, 2013.

FREIRE, J. M.; OLIVEIRA, L. M.; PIÑA-RODRIGUES, F C. M. Vinhático (Plathymenia reticulata Benth.) Londrina: Associação Brasileira de Tecnologia de Sementes - Comitê Técnico de Sementes Florestais, 2017. $5 \mathrm{p}$ (Nota técnica, 01 ).

GIACHINI, R. M.; LOBO, F. A.; ALBUQUERQUE, M. C. F; ORTIZ, E. R. Influência da escarificação e da temperatura sobre a germinação de sementes de Samanea tubulosa (Benth.) Barneby \& J.W. Grimes (sete cascas). Acta Amazonica, Manaus, v. 40, n. 1, p. 75-80, 2010. DOI: http://dx.doi.org/10.1590/S0044-59672010000100010

LABOURIAU, L. G. A germinação das sementes. Washington: Organização dos Estados Americanos, 1983. $174 \mathrm{p}$.

LOPES, R. M. F.; FREITAS, V. L. DE O.; LEMOS FILHO, J. P. Biometria de frutos e sementes e germinação de Plathymenia reticulata benth. e Plathymenia foliolosa benth. (FABACEAE - MIMOSOIDEAE). Revista Árvore, v. 34, n. 5, p. 797-805, 2010. DOI: http://dx.doi.org/10.1590/S0100-67622010000500005
MAGUIRE, J. D. Speed of germination-aid in selection and evaluation for seedlig emergence and vigor. Crop Science, Madison, v. 2, n. 1, p. 176-177, 1962.

MANTOAN, P.; SOUZA LEAL, T.; PESSA, H.; MARTELINE, M. A.; PEDROSO DE MORAES, C. Escarificação mecânica e química na superação de dormência de Adenanthera pavonina L. (Fabaceae: Mimosoideae). Scientia Plena, v. 8, n. 5, p. 1-8, 2012.

NASCIMENTO, I. L.; ALVES, E. A.; BRUNO, R. L. A.; GONÇALVES, E. P.; COLARES, P. N. Q. C.; MEDEIROS, M. S. Superação da dormência em sementes de faveira (Parkia platycephala Benth). Revista Árvore, Viçosa. v. 33, n. 1, p. 35-45, 2009. DOI: http://dx.doi.org/10.1590/S0100-67622009000100005

OLIVEIRA, A. K. M.; RIBEIRO, J. W. F.; PEREIRA, K. C. L., RONDON, E. V.; BECKER, T. J. A.; BARBOSA, L. A. Superação de dormência em sementes de Parkia gigantocarpa (Fabaceae-Mimosidae). Ciência Florestal, Santa Maria, v. 22, n. 3, p. 533-540, 2012. DOI: http://dx.doi.org/10.5902/198050986620

OLIVEIRA, D. A.; NUNES, Y. R. F.; ROCHA, E. A.; BRAGA, R. F.; PIMENTA, M. A. S.; VELOSO, M. D. M. Potencial germinativo de sementes de fava-d'anta (Dimorphandra mollis Benth.- Fabaceae: Mimosoideae) sob diferentes procedências, datas de coleta e tratamentos de escarificação. Revista Árvore, Viçosa, v. 32, n. 6, p. 1001-1009, 2008. DOI: http://dx.doi.org/10.1590/S010067622008000600005

PEREIRA, S. A.; FERREIRA, S. A. N. Superação da dormência em sementes de visgueiro-do-igapó (Parkia discolor). Acta Amazonica, Manaus, v. 40, n. 1, p. 151156, 2010. DOI: http://dx.doi.org/10.1590/S004459672010000100019

PIVETA, G. MENEZES, V. O.; PEDROSO, D. C.; MUNIZ, M. F. B.; BLUME, E.; WIELEWICKI. Superação de dormência na qualidade de sementes e mudas: influência na produção de Senna multijuga (L. C. Rich.) Irwin \& Barneby. Acta Amazonica, Manaus, v. 40, n. 2, p. 281288, 2010. DOI: http://dx.doi.org/10.1590/S004459672010000200006

SANTOS, F.; SCHLINDWEIN, G.; ROSSONI, M.G.; AZAMBUJA, A. C. Influência de processos de escarificação na embebição e germinação de Senna corymbosa (Lam.) H.S. Irwin \& Barneby. Pesquisa Agropecuária Gaúcha, Porto Alegre, v. 14, n. 1, p.57-61, 2008.

SMIDERLE, O. J.; SCHWENGBER, L. A. M. Superação da dormência em sementes de paricarana (Bowdichia virgilioides Kunth.). Revista Brasileira de Sementes, Londrina, v. 33, n. 3, p. 407-414, 2011. DOI: http://dx.doi.org/10.1590/S0101-31222011000300003

VANZOLINI. S.; ARAKI. C. A. S.; SILVA. A. C. T. M.; NAKAGAWA, J. Teste de comprimento de plântula na avaliação da qualidade fisiológica de sementes de soja. Revista Brasileira de Sementes, Londrina, v. 29, n. 2, p. 90-96, 2007. DOI: http://dx.doi.org/10.1590/S010131222007000200012

VIDIGAL, D. S.; LIMA, J. S.; BHERING, M. C.; DIAS, D. C. F. S. Teste de condutividade elétrica para semente de pimenta. Revista Brasileira de Sementes, Londrina, v. 30 , n. $1, \quad$ p. $168-174, \quad 2008$. DOI: http://dx.doi.org/10.1590/S0101-31222008000100021 